\title{
The complementary effect of rs1042522 in TP53 and rs1805007 in $M C 1 R$ is associated with an elevated risk of cutaneous melanoma in Latvian population
}

\author{
AIJA OZOLA $^{1 *}$, DACE RUKLISA $^{2 *}$ and DACE PJANOVA ${ }^{1}$ \\ ${ }^{1}$ Latvian Biomedical Research and Study Centre, Riga LV-1067, Latvia; ${ }^{2}$ Newnham College, University of Cambridge, \\ Cambridge CB3 9DF, United Kingdom
}

Received May 21, 2019; Accepted August 30, 2019

DOI: $10.3892 /$ ol.2019.10906

\begin{abstract}
Genetic factors serve important roles in melanoma susceptibility. Although much genetic variation has been associated with cutaneous melanoma (CM), little is known about the interactions between genetic variants. The current study investigated the joint effect of rs1042522 in the tumour protein 53 (TP53) gene, rs2279744 in the murine double minute-2 (MDM2) gene and several single nucleotide polymorphisms (SNPs) in the melanocortin 1 receptor $(M C 1 R)$ gene. All of these genes are interconnected in a single signalling pathway that regulates pigmentation. The current study included 479 individuals, of which, 255 were patients with CM and 224 were controls from the Latvian population. Multifaceted analyses of potential interactions between SNPs were performed, whilst taking into account the pigmentation phenotypes of individuals and tumour characteristics (Breslow thickness and ulceration). Univariate analyses revealed a borderline significant association between rs1042522 in the TP53 gene and $\mathrm{CM}$ risk. The results also confirmed a known association with rs1805007 in the MC1R gene. The rs1042522 was also selected as a CM risk factor in multivariate models, suggesting an effect that is independent from and complementary to that of rs1805007. The results indicated that these SNPs need to be taken into account when determining melanoma risk. A strong association between CM and red hair was identified for rs1805007, and rs1805008 in the MC1R gene was mainly associated with red hair. An association was also determined between rs2279744 in the MDM2 gene and brown eye colour.
\end{abstract}

Correspondence to: Dr Dace Pjanova, Latvian Biomedical Research and Study Centre, 1 Ratsupites Street 1, k-1, Riga LV-1067, Latvia

E-mail: dace@biomed.lu.lv

*Contributed equally

Key words: melanoma, single nucleotide polymorphism, melanocortin 1 receptor gene, tumor protein 53 gene, murine double minute-2 gene
No convincing associations were identified between the analysed SNPs and Breslow thickness of tumours or ulcerations.

\section{Introduction}

Cutaneous melanoma (CM) is the most malignant type of skin cancers. Its incidence and overall health burden are increasing in Western countries (1). The predisposition to CM and the course of its development depend on complex interactions between environmental factors, phenotype and genotype. The principal environmental risk factor for the pathogenesis of CM is ultraviolet radiation (2). Among the main phenotypic factors contributing to CM are an increased number of nevi and freckles, light skin, fair eyes and red and blonde hair colours-all determined by genetic factors $(3,4)$. Several high-, mediumand low-risk genes are involved in the CM development (5). One of the best-known medium-risk genes is melanocortin 1 receptor gene $(M C 1 R)$ in the locus 16q24.3. MC1R has more than 100 non-synonymous single nucleotide polymorphisms (SNPs) identified so far; many of them have a strong link with an increased risk of CM $(6,7)$ and are also associated with the so-called $\mathrm{R}$ phenotype that is characterized by red hair and fair skin (8). In addition, other SNPs close to the MC1R gene have also been associated with the R phenotype and the CM risk-these include rs258322, rs4785763 and rs8059973 $(9,10)$. $M C 1 R$ is activated by $\alpha$-melanocyte-stimulating hormone $(\alpha-\mathrm{MSH})$ that initiates an intracellular signal cascade leading to the production of the photoprotective pigment melanin (11). $\alpha-\mathrm{MSH}$ is produced in the post-translational processing of the pro-opiomelanocortin (POMC). It has been demonstrated that after UV irradiation the $P O M C$ promoter is activated by one of the major tumour suppressor proteins TP53 (12). Almost half of the human cancers harbour TP53 mutations (13). Furthermore, the TP53 impact on cancer is not limited to somatic mutations and may manifest through germline variants (14). The rs1042522 (p.Pro72Arg, c.215C>G) is located in a proline-rich domain of TP53, which has an important role in the TP53-mediated apoptosis (15). Results from CM association studies show conflicting roles for rs1042522. Associations have been found with both Pro $(16,17)$ and Arg $(18,19)$ alleles. TP53 is negatively regulated by an auto-regulatory feedback loop with E3 ubiquitin ligase MDM2. The MDM2 intron 1 
comprises an alternative promoter P2 for the MDM2 transcription, which is induced by TP53 (20). The rs2279744 $($ c. $14+309 \mathrm{~T}>\mathrm{G})$ is located within this promoter. It has been shown that the $\mathrm{G}$ allele of rs2279744 increases the affinity for the transcription activation factor Sp1 thus leading to an increased MDM2 expression. This in turn causes TP53 inhibition, which might promote tumour formation (21). Association studies for CM have demonstrated a relationship between rs2279744's GG genotype and the CM risk depending on age, sex (22-24) and Breslow thickness (25), although results are not consistent. It means that MC1R, TP53 and MDM2 are interconnected in a shared signalling pathway regulating pigmentation.

In this study, we aim to investigate the joint effect of the SNPs in the MC1R gene and its vicinity and rs1042522 in TP53 and rs227974 in MDM2 in the context of the CM risk prediction. In addition, we explore the associations of these SNPs with pigmentation traits and tumour characteristics, in particular ulceration and Breslow thickness, for their predictive power of disease progression.

\section{Materials and methods}

Study population. We conducted this study using DNA samples and data on individuals from the Latvian Genome Data Base (LGDB), a government-funded biobank (described in (26). These data have been previously explored to assess the variation within the $M C 1 R$ gene and to study particular SNPs on the chromosome 16 (27). In total, 479 samples were selected for this study, including 224 unrelated healthy volunteers and $255 \mathrm{CM}$ patients with histopathologically confirmed CM (ICD-10 diagnosis code C43). An additional criterion for the inclusion of individuals in this study was a completed questionnaire (self-reported) about their pigmentation characteristics: Hair colour, eye colour, skin type, freckles in childhood and adulthood, and nevi. Data about tumour characteristics, such as Breslow thickness and ulceration, were obtained from the medical records of CM patients. All individuals incorporated in the study have European ancestry and represent Latvian population, which is known to be genetically homogeneous (28). Written, informed consent was acquired from all LGDB participants.

Genotyping. The entire coding region of the MC1R gene was sequenced and SNPs on chromosome 16 (rs258322, rs4785763, and rs8059973) were genotyped as described in (27). The TP53 gene exon 4, which contains rs1042522, was amplified using primers 5'-ATCTACAGTCCCCCTTGCGC-3' and 5'-GCAAC TGACCGTGCAAGTCA-3' (18). The intronic promoter region of the MDM2 gene that contains rs2279744 was amplified using primers 5'-CGGGAGTTCAGGGTAAAGGT-3' and 5'-A GCAAGTCGGTGCTTACCTG-3' (21). All primers have been synthesised at the Metabion International AG, Martinsried, Germany. Polymerase chain reactions were performed in a $25 \mu \mathrm{l}$ reaction volume containing $25 \mathrm{ng}$ of template DNA, 1x Taq buffer, $5 \%$ dimethyl sulfoxide, $1.5 \mathrm{mM}$ magnesium chloride, $0.24 \mathrm{mM}$ dNTPs, $0.4 \mu \mathrm{M}$ of each primer and $1.25 \mathrm{U}$ TaqDNA Polymerase (Thermo Scientific Molecular Biology). The cycling conditions were as follows: An initial denaturation at $95^{\circ} \mathrm{C}$ for ten minutes; 35 cycles of denaturation at $95^{\circ} \mathrm{C}$ for
$30 \mathrm{sec}$, annealing at $62^{\circ} \mathrm{C}$ and $55^{\circ} \mathrm{C}$ (for TP53 and $M D M 2$, respectively) for $30 \mathrm{sec}$ and extension at $72^{\circ} \mathrm{C}$ for one minute followed by a final extension at $72^{\circ} \mathrm{C}$ for seven minutes. The sequencing was done in both directions with the primers that were used for amplification. ABI PRISM BigDye Terminator cycle sequencing kit (Applied Biosystems) was applied in the following conditions: 25 cycles at $94^{\circ} \mathrm{C}$ for $30 \mathrm{sec}$, then at $53^{\circ} \mathrm{C}$ for $15 \mathrm{sec}$, and at $60^{\circ} \mathrm{C}$ for four minutes. Initial analysis was carried out on an ABI PRISM 3100 Genetic analyser according to manufacturer's instructions (Applied Biosystems). Sequence analysis was performed and confirmed manually using the Vector NTI (Life Technologies).

Statistical analyses. The associations between demographic characteristics, pigmentation traits (hair colour, eye colour, skin type, freckles in childhood, freckles in adulthood and nevi) and CM were assessed either by the Chi-squared test or Fisher's exact test. The age distributions for cases and controls were compared by the Mann-Whitney test. The minor allele frequency (MAF) of a SNP was estimated from all controls having the genotype information for this particular SNP (224 controls for the MC1R gene SNPs, 203 for rs258322, 205 for rs4785763, 217 for rs1042522 and 215 for rs2279744). In subsequent analyses we included only the SNPs that had $\geq 4 \% \mathrm{MAF}$ and at least one homozygote of two minor alleles in controls and also did not significantly deviate from the Hardy-Weinberg equilibrium. Genotyping failed for rs1042522 in one case and for rs2279744 in another case. These two samples were excluded from further analyses. Hence, $253 \mathrm{CM}$ cases and 200 controls having genotype information for all selected SNPs were included in the analyses.

First, univariate association analyses were carried out using logistic regression models with and without cofactors (age and sex). Throughout all analyses an additive model of the contribution of alleles was assumed. Models were fitted using the function $\mathrm{glm}$ in $\mathrm{R}$ environment. The model without cofactors was $\log (\mathrm{P}(\mathrm{Y}=1) /(1-\mathrm{P}(\mathrm{Y}=1)))=\mu+\beta \cdot \mathrm{X}+\varepsilon$ where $\mathrm{Y}$ was melanoma status, $\mathrm{X}$ was the genotype vector for all individuals, $\mu$ was a constant intercept, $\beta$ measured the effect of the genotype upon melanoma status and $\varepsilon$ was the vector of error terms.

The model with cofactors was $\log (\mathrm{P}(\mathrm{Y}=1) /(1-\mathrm{P}(\mathrm{Y}=1)))$ $=\mu+\gamma \cdot \mathrm{G}+\alpha \cdot \mathrm{A} / 100+\beta \cdot \mathrm{X}+\varepsilon$ where $\mathrm{G}$ was the sex vector and $\gamma$ the effect of sex and A was the vector of ages in years and $\alpha$ the effect of age; other variables as defined above.

The significance of an association between a SNP and CM was measured by the Wald test that was applied to the SNP term with $\alpha=0.05$. A permutation test was carried out to check whether the observed level of association was significant (Supplementary Material).

Multivariate models with and without cofactors (age and sex) were built by stepwise regression using the function stepAIC from the R package MASS. The AIC criterion was applied to assess the significance of a model improvement after either adding or removing of a predictor. A generalised linear model was used throughout all multivariate analyses. A multivariate model without cofactors was of the form $\log (\mathrm{P}(\mathrm{Y}=1) /(1-\mathrm{P}(\mathrm{Y}=1)))=\mu+\beta_{1} \cdot \mathrm{X}_{1}+\cdots+\beta_{\mathrm{k}} \cdot \mathrm{X}_{\mathrm{k}}+\varepsilon$ where $\mathrm{X}_{\mathrm{k}}$ was the vector of genotypes for SNP $k$ and $\beta_{k}$ was the effect of SNP k. A multivariate model with cofactors had the form 
$\log (\mathrm{P}(\mathrm{Y}=1) /(1-\mathrm{P}(\mathrm{Y}=1)))=\mu+\gamma \cdot \mathrm{G}+\alpha \cdot \mathrm{A} / 100+\beta_{1} \cdot \mathrm{X}_{1}+\cdots+\beta_{\mathrm{k}} \cdot \mathrm{X}_{\mathrm{k}}+\varepsilon$ with notation as specified above.

In addition, for each SNP (rs2228479, rs1805007, rs1110400, rs1805008, rs258322, rs4785763), three multivariate models were built that incorporated one of these SNPs and either one or both of the rs1042522 and rs2279744. These models were:

$\log (\mathrm{P}(\mathrm{Y}=1) /(1-\mathrm{P}(\mathrm{Y}=1)))=\mu+\beta_{1} \cdot \mathrm{X}_{1}+\beta_{\mathrm{s}} \cdot \mathrm{X}_{\mathrm{s}}+\varepsilon$

$\log (\mathrm{P}(\mathrm{Y}=1) /(1-\mathrm{P}(\mathrm{Y}=1)))=\mu+\beta_{2} \cdot \mathrm{X}_{2}+\beta_{\mathrm{s}} \cdot \mathrm{X}_{\mathrm{s}}+\varepsilon$

$\log (\mathrm{P}(\mathrm{Y}=1) /(1-\mathrm{P}(\mathrm{Y}=1)))=\mu+\beta_{1} \cdot \mathrm{X}_{1}+\beta_{2} \cdot \mathrm{X}_{2}+\beta_{\mathrm{s}} \cdot \mathrm{X}_{\mathrm{s}}+\varepsilon$

Here, $X_{1}$ was the vector of the rs1042522 genotypes and $\beta_{1}$ measured their effect, $X_{2}$ was the vector of the rs 2279744 genotypes having the effect $\beta_{2}$, and $X_{s}$ and $\beta_{\mathrm{s}}$ were the genotypes and the effect of the chosen SNP.

The associations of SNPs with pigmentation traits were tested as well. In these analyses, we used either only controls or solely CM cases. The strength of each association was evaluated by Fisher's exact test and empirical P-values were obtained by a permutation test (see Supplementary Material). In order to understand simultaneous effects of individual SNPs upon pigmentation traits and the CM status we used ordinal regression approach. We modelled a genotype as an ordinal outcome and included both the CM status and a pigmentation trait as predictors in a regression model according to the method described in (29). Each model was fitted by the function $c l m$ from the $\mathrm{R}$ package ordinal. The significance of each likelihood ratio obtained from a comparison of two models, with and without the CM status and a pigmentation trait, was assessed using a permutation test (Supplementary Material).

The associations between SNPs and tumour Breslow thickness and ulceration were explored using the patients that had the information on the studied tumour characteristic-195 cases for Breslow thickness and 147 cases for ulceration (68 with and 79 without ulceration). A linear regression model was used to describe the association between a SNP and the logarithm of Breslow thickness (exploratory analyses showed that the logarithm of Breslow thickness roughly corresponds to a normal distribution). The model was $\log (\mathrm{R})=\mu+\beta \cdot \mathrm{X}+\varepsilon$ where $\mathrm{R}$ was a vector of the Breslow thicknesses and other terms were defined as for univariate models of genotype and CM associations.

The impact of a SNP on Breslow thickness was assessed by the t-test that was applied to the SNP term. The models were fitted by the function $l m$ in R environment.

A generalised linear model was used to relate a SNP to ulceration: $\log (\mathrm{P}(\mathrm{U}=1) /(1-\mathrm{P}(\mathrm{U}=1)=\mu+\beta \cdot \mathrm{X}+\varepsilon$ where $\mathrm{P}(\mathrm{U}=1)$ was the probability of ulceration and other terms were as defined for univariate models of genotype and CM associations. The significance of an association was determined by the Wald test applied to the genotype term. For Breslow thickness, age was chosen as a cofactor, while for ulceration both age and sex were incorporated in models. The two models with cofactors were

$\log (\mathrm{R})=\mu+\alpha \cdot \mathrm{A} / 100+\beta \cdot \mathrm{X}+\varepsilon$ and

$\log (\mathrm{P}(\mathrm{U}=1) /(1-\mathrm{P}(\mathrm{U}=1)=\mu+\gamma \cdot \mathrm{G}+\alpha \cdot \mathrm{A} / 100+\beta \cdot \mathrm{X}+\varepsilon$ with the notation as above. Empirical P-values obtained from a permutation test were reported for the associations with Breslow thickness and ulceration (Supplementary Material).

\section{Results}

Demographic and pigmentation characteristics of the study population. Associations between the demographic and pigmentation characteristics of the study participants (253 cases and 200 controls) and CM are summarised in Table I. CM patients and controls did not differ in terms of sex $(\mathrm{P}=0.149)$, while the control group was younger than patients (Mann-Whitney test $\left.\mathrm{P}=1.15 \times 10^{-7}\right)$. The strongest association with an increased $\mathrm{CM}$ risk was observed for skin type $\left(\mathrm{P}=5.74 \times 10^{-9}\right)$, followed by nevi $\left(\mathrm{P}=7.46 \times 10^{-5}\right)$ and freckles, both in adulthood and childhood ( $\mathrm{P}=0.001$ and 0.01 respectively).

Genotyping results. Both SNPs genotyped within this study (rs1042522 (Pro72Arg, c.215C>G) in TP53 and rs2279744 (c.14+309T $>$ G) in $M D M 2$ ) reached $4 \%$ MAF, had at least one homozygote of two minor alleles among controls and were in Hardy-Weinberg equilibrium (data not shown). Thus both SNPs were included in further analyses and were studied together with the six previously selected SNPs on chromosome 16, namely rs2228479 (p.Val92Met, c.274G>A), rs1805007 (p.Arg151Cys, c.451C>T), rs1110400 (p.Ile155Thr, c.464T >C) and rs1805008 (p.Arg160Trp, c.478C >T) in the $M C 1 R$ gene, as well as $\operatorname{rs} 258322(\mathrm{c} .160+171 \mathrm{~A}>\mathrm{G})$ in the CDK10 gene, and rs4785763 (n.1682A >C) in the AFG3L1P pseudogene. Among the SNPs that passed the minor allele frequency threshold there were none with several alternative alleles. Other MC1R SNPs found in our cohort did not pass the inclusion criteria for further analyses (4\% MAF and at least one homozygote of two minor alleles among controls). These included 13 non-synonymous SNPs, rs1805005 (Val60Leu, c.178G>T), rs777024553 (Ser83Leu, c.248C >T), rs1805006 (Asp84Glu, c.252C>A), rs34540312 (Gly89Arg, c.265G>C), rs34158934 (Thr95Met, c.284C >T), rs200616835 (Asp121Glu, c.363C >G), rs11547464 (Arg142His, c.425G>A), rs885479 (Arg163Gln, c.488G>A), rs762096175 (Val165Ile, c.493G>A), rs780875127 (c.495_496insGG), rs530102853 (Asp184His, c.550G>C), rs774680166 (Val188Ile, c.562G>A), rs200000734 (Arg213Trp, c.637C >T), as well as seven synonymous SNPs, rs201429598 (Cys133=, c.399C $>$ T), rs201827012 (Arg151=, c.453C >G), rs374959395 (Ala166=, c.498G>A), rs146544450 $(\mathrm{Gln} 233=$, c.699G $>$ A), rs375813196 (Cys273=, c.819C $>$ T), rs2228478 (Thr314=, c.942A $>$ G), rs151318945 (Ser316=, c.948C $>$ T). The MAFs of these variants are shown in the supplementary Table SI.

SNP associations with CM. Among the newly genotyped SNPs, only the rs1042522 in TP53 showed a borderline significant association with $\mathrm{CM}$ in the univariate analysis $(\mathrm{P}=0.065)$. However, this association was not significant according to a permutation test and became weaker after adjustment for age and sex (Table II). Notable associations with CM were displayed by the rs 1805007 within $\operatorname{MClR}(\mathrm{P}=0.009)$, as well as rs258322 and rs4785763 ( $\mathrm{P}=0.012$ and $\mathrm{P}=0.021$, respectively). A permutation test confirmed the associations for rs 1805007 and rs258322 as moderately significant (empirical $\mathrm{P}=0.051$ 
Table I. Associations between demographic data, pigmentation characteristics and cutaneous melanoma status within the study cohort.

\begin{tabular}{|c|c|c|c|c|c|}
\hline \multirow[b]{2}{*}{ Characteristic } & \multicolumn{2}{|c|}{ Controls $(\mathrm{n}=200)$} & \multicolumn{2}{|c|}{$\begin{array}{c}\text { Melanoma } \\
\text { patients }(n=253)\end{array}$} & \multirow[b]{2}{*}{ P-value } \\
\hline & $\mathrm{n}$ & $(\%)$ & $\mathrm{n}$ & $(\%)$ & \\
\hline \multicolumn{6}{|l|}{ Sex } \\
\hline Female & 150 & $(75.0)$ & 173 & $(68.4)$ & $0.149^{\mathrm{a}}$ \\
\hline Male & 50 & $(25.0)$ & 80 & (31.6) & \\
\hline Age & \multicolumn{2}{|c|}{$47.5 \pm 17.5$} & \multicolumn{2}{|c|}{$56.4 \pm 15.0$} & $1.15 \times 10^{-7 c}$ \\
\hline \multicolumn{6}{|l|}{ Hair colour } \\
\hline Red & 5 & (2.5) & 16 & (6.3) & $0.070^{\mathrm{b}, \mathrm{d}}$ \\
\hline Fair & 72 & $(36.0)$ & 126 & $(49.8)$ & \\
\hline Brown & 109 & $(54.5)$ & 96 & $(37.9)$ & \\
\hline Black & 11 & (5.5) & 9 & (3.6) & \\
\hline nd & 3 & (1.5) & 6 & (2.4) & \\
\hline \multicolumn{6}{|l|}{ Skin type } \\
\hline I & 7 & (3.5) & 28 & $(11.0)$ & $5.74 \times 10^{-9 b}$ \\
\hline II & 28 & $(14.0)$ & 72 & $(28.5)$ & \\
\hline III & 144 & $(72.0)$ & 107 & $(42.3)$ & \\
\hline IV & 19 & (9.5) & 41 & $(16.2)$ & \\
\hline nd & 2 & $(1.0)$ & 5 & $(2.0)$ & \\
\hline \multicolumn{6}{|l|}{ Eye colour } \\
\hline Blue & 62 & $(31.0)$ & 104 & $(41.1)$ & $0.605^{\mathrm{e}}$ \\
\hline Grey & 50 & $(25.0)$ & 37 & $(14.6)$ & \\
\hline Green & 25 & $(12.5)$ & 30 & $(11.9)$ & \\
\hline Brown & 29 & $(14.5)$ & 30 & $(11.9)$ & \\
\hline Other & 29 & $(14.5)$ & 47 & $(18.5)$ & \\
\hline nd & 5 & $(2.5)$ & 5 & $(2.0)$ & \\
\hline \multicolumn{6}{|c|}{ Freckles in childhood } \\
\hline Very many/many & 7 & (3.5) & 21 & (8.3) & $0.010^{\mathrm{b}}$ \\
\hline Some & 7 & (3.5) & 7 & $(2.8)$ & \\
\hline Few & 22 & $(11.0)$ & 37 & $(14.6)$ & \\
\hline Very few & 52 & $(26.0)$ & 86 & $(34.0)$ & \\
\hline None & 105 & $(52.5)$ & 96 & $(37.9)$ & \\
\hline nd & 7 & $(3.5)$ & 6 & $(2.4)$ & \\
\hline \multicolumn{6}{|c|}{ Freckles in adulthood } \\
\hline Very many/many & 8 & $(4.0)$ & 16 & $(6.3)$ & $0.001^{\mathrm{b}}$ \\
\hline Some & 7 & (3.5) & 6 & (2.4) & \\
\hline Few & 18 & $(9.0)$ & 31 & $(12.3)$ & \\
\hline Very few & 46 & $(23.0)$ & 79 & $(31.2)$ & \\
\hline None & 119 & $(59.5)$ & 89 & $(35.2)$ & \\
\hline nd & 2 & $(1.0)$ & 32 & $(12.6)$ & \\
\hline \multicolumn{6}{|l|}{ Nevi } \\
\hline Many & 25 & $(12.5)$ & 71 & $(28.0)$ & $7.46 \times 10^{-5 a}$ \\
\hline Some & 69 & $(34.5)$ & 70 & $(27.7)$ & \\
\hline Few & 93 & $(46.5)$ & 83 & $(32.8)$ & \\
\hline None & 11 & $(5.5)$ & 23 & $(9.1)$ & \\
\hline nd & 2 & $(1.0)$ & 6 & (2.4) & \\
\hline
\end{tabular}

$\mathrm{P} \leq 0.05$ are indicated in bold. P-values were obtained via ${ }^{\mathrm{a}} \mathrm{Chi}$-squared tests, ${ }^{\mathrm{b}}$ Fisher's exact tests and ${ }^{\mathrm{c}}$ Mann-Whitney tests. ${ }^{\mathrm{d}}$ Red hair colour was compared with all other hair colours. 'brown eyes were compared with all other eye colours, where 'other' colours were excluded from the comparison. Skin types correspond to the following: I, always burns and never tans; II, usually burns and sometimes tans; III, sometimes burns and usually tans; IV, never burns and always tans. nd, no data. 


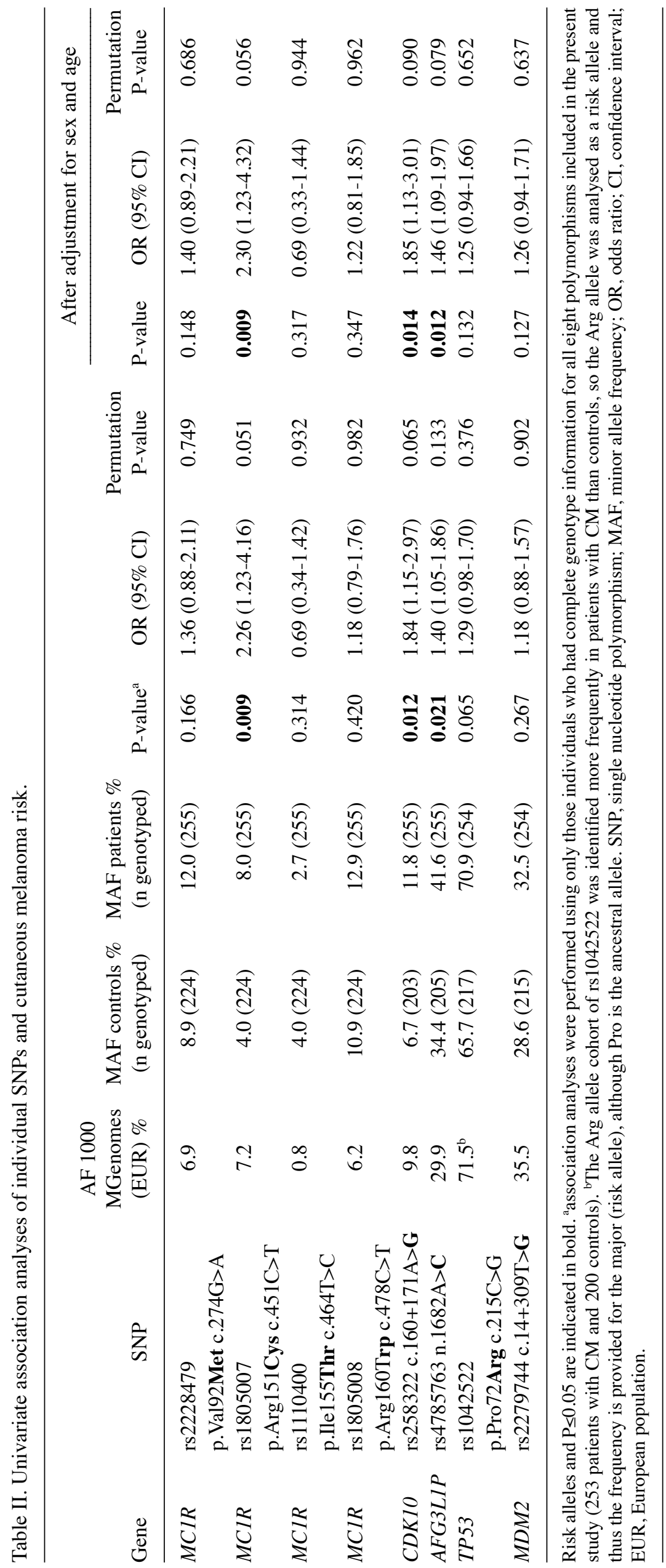



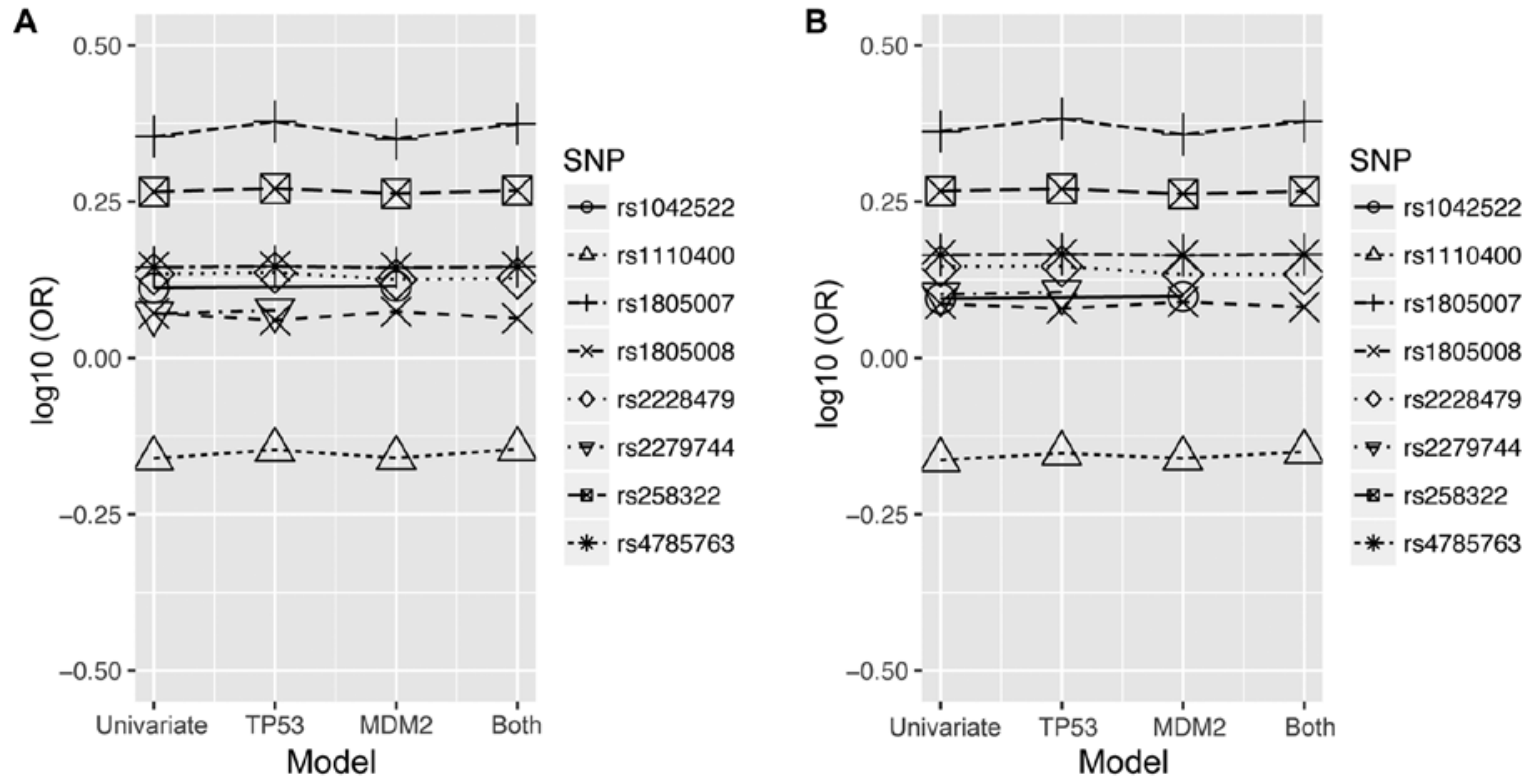

Figure 1. Estimated ORs for individual SNPs from univariate models and models involving rs 1042522 from TP53 and/or rs2279744 from MDM2. (A) log 10 ORs from models without cofactors. (B) $\log _{10}$ ORs from cofactor models in which age and sex were included. OR, odds ratio; TP53, tumor protein 53; MDM2, murine double minute-2; MCR1, melanocortin 1 receptor.

Table III. SNPs associated with cutaneous melanoma selected by stepwise regression.

A, Regression model without cofactors

\begin{tabular}{lcccc}
\hline Gene & SNP & P-value & OR & $95 \%$ CI \\
\hline MC1R & rs1805007 & 0.005 & 2.43 & $1.31-4.50$ \\
TP53 & rs1042522 & 0.035 & 1.35 & $1.02-1.78$ \\
MC1R & rs2228479 & 0.126 & 1.41 & $0.91-2.19$ \\
\hline
\end{tabular}

B, Regression model with cofactors (age and sex)

\begin{tabular}{lcccc}
\hline Gene & SNP & P-value & OR & $95 \%$ CI \\
\hline MC1R & rs1805007 & 0.036 & 2.03 & $1.05-3.93$ \\
TP53 & rs1042522 & 0.083 & 1.32 & $0.96-1.80$ \\
AFG3L1P & rs4785763 & 0.079 & 1.30 & $0.97-1.74$ \\
MDM2 & rs2279744 & 0.133 & 1.26 & $0.93-1.72$ \\
\hline
\end{tabular}

MC1R, melanocortin 1 receptor; TP53, tumor protein 53; MDM2, murine double minute-2; SNP, single nuclear polymorphism; $\mathrm{OR}$, odds ratio; CI, confidence interval.

and $\mathrm{P}=0.065$, respectively). Results were similar after the inclusion of age and sex as cofactors and revealed a more convincing association with the CM status for rs4785763 $(\mathrm{P}=0.012$ ) (Table II).

Three SNPs were selected for the multivariate model without cofactors-rs1805007 and rs2228479 from MC1R, as well as rs1042522 from TP53 (P-values 0.005, 0.126 and 0.035, respectively) (Table III). This suggests that the effects of these SNPs on the CM risk might be rather independent and complementary to each other. After the inclusion of cofactors (age and sex) in the model, four SNPs were selected (Table III). The rs1805007 in MClR remained significant, and rs1042522 in TP53 showed a borderline significant association. Two novel association signals were identified-rs4785763 and rs2279744 in the MDM2 gene. Both of them seem to have small effects, independent from rs1805007 and rs1042522, which might also have some interplay with age and sex (Table III).

In the latter multivariate model age emerged as a significant risk factor for $\mathrm{CM}$ with $\mathrm{P}=1.44 \times 10^{-8}$ ( $\mathrm{OR}=34.64$, 95\% $\mathrm{CI}=10.17-118.00$ ) and sex also differentiated the risk with a borderline significance $(\mathrm{P}=0.050, \mathrm{OR}=1.56,95 \% \mathrm{CI}=1.00-2.42)$.

To understand the interactions between rs1042522 and rs2279744 and their impact on the CM risk in combination with $M C 1 R$ and other chromosome 16 SNPs, further multivariate models were fitted. Fig. 1 shows the changes in the logarithm of the odds ratio (OR) for each SNP depending on the context of a model. The highest impact on the CM risk was consistently displayed by rs 1805007 within $M C 1 R$ having $\log 10(\mathrm{OR})=0.35$; its effect became more prominent when it was accompanied by the rs1042522 of TP53: $\log 10(\mathrm{OR})=0.37$ (Fig. 1A). This trend was not significantly altered by the presence of cofactors, age and sex (Fig. 1B). Other types of potential interactions are unlikely due to flat $\log 10(\mathrm{OR})$ trends depicted in Fig. 1 .

Associations between SNPs, pigmentation traits and melanoma. We searched for associations between individual SNPs and pigmentation traits within the set of controls first. We found associations between rs1805007 in the MC1R gene and red hair colour (empirical $\mathrm{P}=0.040$ ) as well as with skin types I and II (empirical P=0.049). In addition, the rs 2279744 from $M D M 2$ was associated with brown eye colour (empirical $\mathrm{P}=0.015$ ) (data not shown).

Next, associations were identified simultaneously for each pigmentation trait and the CM status. Three different SNPs emerged as significant from this analysis (Table IV). The $M C 1 R$ rs1805007 was associated with CM and with red hair as 
well with the skin types I and II and the presence of freckles in childhood. The rs 1805008 in $M C 1 R$ was strongly associated with red hair and also related to the presence of freckles in childhood. However, this SNP did not exhibit any prominent relationship with $\mathrm{CM}$, which implies that it primarily determines the pigmentation traits. Furthermore, rs2279744 from MDM2 displayed an association with brown eye colour and no convincing association with $\mathrm{CM}$ (Table IV).

Associations between SNPs and tumour characteristics. We also looked at the connections between the eight selected SNPs and tumour ulceration and Breslow thickness. The only SNP that showed an association with ulceration was rs4785763-its alternative allele displayed a protective effect $(\mathrm{P}=0.038, \mathrm{OR}=0.58,95 \% \mathrm{CI}=0.35-0.97)$. The effect became less pronounced after the adjustment for age and sex $(\mathrm{P}=0.125$, $\mathrm{OR}=0.66,95 \% \mathrm{CI}=0.38-1.12$ ). However, according to a permutation test this association was not significant. Associations with Breslow thickness were exhibited by two $M C 1 R$ SNPs-rs2228479 and rs1110400. These associations remained consistent in models with and without cofactors. The rs 1110400 was associated with thicker tumours $(\mathrm{P}=0.035, \mathrm{OR}=2.49$, 95\% $\mathrm{CI}=1.07-5.77$ and $\mathrm{P}=0.027, \mathrm{OR}=2.60,95 \% \mathrm{CI}=1.12-6.00$ for models without and with cofactors, respectively), and rs2228479 was related to thinner tumours $(\mathrm{P}=0.036, \mathrm{OR}=0.69$, 95\% $\mathrm{CI}=0.48-0.97$ and $\mathrm{P}=0.037, \mathrm{OR}=0.69,95 \% \mathrm{CI}=0.49-0.98$ for models without and with cofactors, respectively). However, after applying a permutation test, these associations became weaker and lost their significance.

\section{Discussion}

In this paper, we explored the associations between $\mathrm{CM}$ and SNPs in the TP53 (rs1042522) and the MDM2 (rs2279744) genes alongside the SNPs in the MCIR gene and other chromosome 16 SNPs previously shown to modify the CM risk in the population of Latvia. The strongest association with CM was consistently displayed by the rs1805007 of MCIR . The association of this SNP with CM has been discovered in numerous studies of various populations across the world with overall $\mathrm{OR}=1.80$ (95\% CI=1.58-2.06) (30). This OR is slightly lower than the one observed in our study $(\mathrm{OR}=2.26$, 95\% CI=1.23-4.16). However, ORs similar to ours were obtained for the geographically close Swedish population $(\mathrm{OR}=2.32,95 \% \mathrm{CI}=1.77-3.05)(31)$ as well as for $\mathrm{Dutch}(\mathrm{OR}=2.5$, 95\% CI=1.4-4.5) (32), French (OR=2.35, 95\% CI=1.78-3.11, $\left.\mathrm{P}=5.10 \times 10^{-10}\right)(33)$, and Spanish $(\mathrm{OR}=2.71,95 \% \mathrm{CI}=1.63-4.52$, $\mathrm{P}=0.00013)$ (31) populations.

A moderately significant association was found for another chromosome 16 SNP, rs258322. However, this SNP has been shown to be linked with the MCIR SNPs, rs1805007, rs1805008 and rs1805009 (p.Asp294His, c.880G>C), all of them associated with an increased CM risk $(10,27,34,35)$. Previously, we have shown that rs4785763 is associated with CM in Latvian population as well (27). Here, we confirm this by the multivariate model that includes age and sex. One of the limitations of the current study is the small number of individuals, which might hinder discovering SNPs with minor effects on CM. However, multivariate models can be more sensitive in elucidating various association signals and can 
reveal weaker associations more clearly after conditioning on a few strongly associated SNPs. This might also be the reason why, according to a univariate analysis, the rs1042522 within TP53 seems to be associated with CM only moderately, but is included in a multivariate model. Moreover, rs1042522 emerged as significant even after rs1805007 had entered the model. These observations suggest that rs1042522 has a small and independent effect on the $\mathrm{CM}$ risk with respect to rs1805007.

Interestingly enough, we found an association between the CM risk and rs1042522's Arg allele, which is the most frequent allele of this SNP in our cohort. Indeed, the Arg allele is more prevalent in individuals having light skin and living in higher latitudes while the ancestral Pro allele is more widespread in populations with darker skin that live closer to equator, most probably due to evolutionary selection (36). The association of rs1042522 with CM has been reported for both alleles in literature. For example, Shen et al (2003) showed an association between CM and the Arg/Arg genotype in the US population ( $\mathrm{OR}=1.43,95 \% \mathrm{CI}=1.02-2.02)$ (18). This association was especially strong in individuals older than 50 years $(\mathrm{OR}=2.32,95 \% \mathrm{CI}=1.39-3.88)$. Later Li et al (2008) confirmed this association in a larger US-based study $(\mathrm{OR}=1.28$, 95\% CI=1.05-1.55) (19). The Arg/Arg homozygote has also been associated with $\mathrm{CM}$ in a Brazilian population $(\mathrm{OR}=1.76$, 95\% $\mathrm{CI}=1.09-2.83, \mathrm{P}=0.020)(37)$ and a small effect attributable to the Arg allele was also identified when analysing specific genotype subgroups (Arg/Pro vs. Pro/Pro) (38). Several studies have shown an association between CM and the Pro allele. Such an association has been found in German $(\mathrm{OR}=2.49,95 \% \mathrm{CI}=1.30-4.75, \mathrm{P}=0.006)$ (39) and Greek populations $(\mathrm{OR}=3.17,95 \% \mathrm{CI}=1.03-9.78)$ (17). There are also studies that have not found associations between any of the rs1042522 alleles and the CM risk-a Dutch population study (40), US Nurses' Health Study (16), a Scottish study (41) and Italian population studies (25). To our knowledge, there is only one study in which the relationships between rs1042522 and the $M C 1 R$ gene SNPs have been analysed. The authors of this study found that the association with the CM risk became stronger for the Pro/Pro genotype in the absence of such MC1R SNPs as rs1805007, rs1805008 and rs1805009, which are related to red hair $(\mathrm{OR}=2.99,95 \% \mathrm{CI}=1.02-8.78)$ (17). More recently, it has also been shown that mutations in TP53 gene are associated with faster progression and poorer overall survival as well as with weaker response to the anti-CTLA-4 therapy in melanoma (42). These observations indicate a possible role of the TP53 gene in predicting the outcome of a therapy.

Interestingly, rs2228479 within MC1R displayed a small effect on $\mathrm{CM}$ in a multivariate model, suggesting it might have an independent impact on the CM risk. However, after the cofactors, age and sex, were included in the model, the effect of rs2228479 disappeared. Previous studies of the involvement of this SNP in the modification of the CM risk report contrasting results. A meta-analysis did not find an association of rs2228479 with CM (43). Subsequent meta-analyses revealed that rs2228479 is associated with $\mathrm{CM}$ and has a small OR (1.08-1.32) (7,30). Hence the effect of this SNP on the CM development is still controversial.

Another SNP that entered a multivariate model was rs2279744 from MDM2. Moreover,rs2279744 was incorporated only in the model with cofactors suggesting some interplay between this SNP and age and/or sex. Previous studies also show some evidence for an age- and sex-dependent effect of rs2279744 on CM, although their results are not consistent. A couple of studies have demonstrated an association between rs2279744's minor allele homozygote GG and the CM risk, especially for younger women or women with a hereditary CM $(22,24)$. In contrast, another study showed that women with the GG genotype might actually be at lower risk of developing CM at a young age (23). Most studies do not tend to find a convincing association between this SNP in the MDM2 gene and the CM risk (25,44-46).

As expected, we identified associations between CM and skin type, nevi, freckles and hair colour. Notably we have a larger proportion of dark skinned individuals with skin types III and IV in the control group than in the case group. The former proportion within controls is unexpected in the light-skinned population of Latvia. This might be explained by the fact that pigmentation traits were self-reported. It also means that it was important to include skin type as a cofactor when assessing associations between genotypes and melanoma. We have done thus when looking at the associations between SNPs, pigmentation traits and melanoma. The results revealed that one of the analysed SNPs was associated with both skin type and melanoma; for other variants skin type was not relevant and did not seem to introduce any bias. The lowest estimate of the OR for rs1805007 and melanoma (OR=2.07) might be more precise than other estimates of ours because it takes into account skin type.

One of the major pigmentation regulators is $M C 1 R$. Previously several MCIR SNPs have been associated both with CM and red hair or fair skin, e.g. rs1805006 (p.Asp84Glu, c. $252 \mathrm{C}>\mathrm{A}$ ), rs11547464 (p.Arg142His, c.425G>A), rs1805007, rs1805008, and rs1805009 (43). We also found an association between the most strongly CM-associated SNP in our study, rs1805007, and red hair and fair skin as well as with the presence of freckles in childhood. Yet another MC1R SNP, rs1805008, was associated with red hair only. The associations of this SNP were consistent throughout all, univariate and multivariate, analyses performed with this study. This result is somewhat different to other studies. It seems that in our cohort the increased melanoma risk for individuals carrying the rs1805008 alternative allele is attributable to the presence of freckles and the red hair phenotype. In addition, rs2279744 in MDM2 displayed an association with brown eye colour. To our knowledge, only one study has looked at the association between rs2279744 and eye colour in CM patients. In that study, genotypes with $\mathrm{G}$ allele (TG and GG) were found more often in patients with dark eyes (45), which is similar to our results.

Several studies have shown that the presence of $M C 1 R$ SNPs is associated with tumour thickness-associations have been demonstrated both with thicker (47-49) and thinner tumours (50). Similarly, rs2279744 from MDM2 has been shown to increase the MDM2 expression (21), which in turn has been linked to the CM thickness (51). The GG genotype of rs2279744 turned out to be significantly associated with $\mathrm{CM}$ in patients having tumours thicker than $0.75 \mathrm{~mm}$ (25). In the latter study, the association between Breslow thickness and rs1042522 in TP53 was also assessed and not found (25). 
In this study, we were not able to show a convincing association between any of the SNPs analysed and Breslow thickness, as none of them could be validated by a permutation test. Associations between MC1R SNPs, in particular the so-called ' $R$ ' variants, and ulceration have also been described (49). However, we were not able to confirm these in our cohort. The rs4785763 from chromosome 16 initially showed an association with ulceration but did not withstand a permutation test. So far no associations have been found between rs2279744 in MDM2 or rs1042522 in TP53 and ulceration (24), and our results confirmed this. Larger cohorts of individuals with less missing data on tumour features would be necessary to draw definite conclusions about such associations.

To conclude, we have demonstrated that rs1042522 within TP53 has an independent effect on the CM risk, which complements the effect of the strongly associated rs1805007 residing in $M C 1 R$. Both of these SNPs needs to be taken into account in melanoma risk calculation. The rs 2279744 in MDM2 is associated with eye colour and has a small, if any, effects towards $\mathrm{CM}$ in Latvian population.

\section{Acknowledgements}

Not applicable.

\section{Funding}

The current study was supported by TRANSCAN via The State Education Development Agency, Republic of Latvia (grant no. GENMEL Z/15/1285 - PRL15/15).

\section{Availability of data and materials}

The datasets used and/or analysed in the present study are available from the corresponding author upon a reasonable request.

\section{Authors' contributions}

AO performed genotyping and data analysis. DR performed statistical analyses and interpreted results. DP conceived and designed the current study, and interpreted the data. All authors wrote, edited and approved the final manuscript.

\section{Ethics approval and consent to participate}

The Central Medical Ethics Committee of Latvia approved the protocols for sample collection (approval nos. A-3/2006 and A-7/2007), which were part of the project 'Creation of Genome Data Base of Latvian population' (protocol no. 01-29/2016-1-1).

\section{Patient consent for publication}

Not applicable.

\section{Competing interests}

The authors declare that they have no competing interests.

\section{References}

1. Whiteman DC, Green AC and Olsen CM: The growing burden of invasive melanoma: Projections of incidence rates and numbers of new cases in six susceptible populations through 2031. J Invest Dermatol 136: 1161-1171, 2016.

2. Gilchrest BA, Eller MS, Geller AC and Yaar M: The pathogenesis of melanoma induced by ultraviolet radiation. N Engl J Med 340: 1341-1348, 1999.

3. Gandini S, Sera F, Cattaruzza MS, Pasquini P, Abeni D, Boyle P and Melchi CF: Meta-analysis of risk factors for cutaneous melanoma: I. Common and atypical naevi. Eur J Cancer 41: 28-44, 2005.

4. Gandini S, Sera F, Cattaruzza MS, Pasquini P, Zanetti R, Masini C, Boyle P and Melchi CF: Meta-analysis of risk factors for cutaneous melanoma: III. Family history, actinic damage and phenotypic factors. Eur J Cancer 41: 2040-2059, 2005.

5. Read J, Wadt K and Hayward NK: Melanoma genetics. J Med Genet 53: 1-14, 2016.

6. Pérez Oliva AB, Fernéndez LP, Detorre C, Herráiz C, Martínez-Escribano JA, Benítez J, Lozano Teruel JA, García-Borrón JC, Jiménez-Cervantes $\mathrm{C}$ and Ribas G: Identification and functional analysis of novel variants of the human melanocortin 1 receptor found in melanoma patients. Hum Mutat 30: 811-822, 2009.

7. Williams PF, Olsen CM, Hayward NK and Whiteman DC: Melanocortin 1 receptor and risk of cutaneous melanoma: A meta-analysis and estimates of population burden. Int J Cancer 129: 1730-1740, 2011.

8. Duffy DL, Box NF, Chen W, Palmer JS, Montgomery GW, James MR, Hayward NK, Martin NG and Sturm RA: Interactive effects of MC1R and OCA2 on melanoma risk phenotypes. Hum Mol Genet 13: 447-461, 2004.

9. Bishop DT, Demenais F, Iles MM, Harland M, Taylor JC, Corda E, Randerson-Moor J, Aitken JF, Avril MF, Azizi E, et al: Genome-wide association study identifies three loci associated with melanoma risk. Nat Genet 41: 920-925, 2009.

10. Han J, Kraft P, Nan H, Guo Q, Chen C, Qureshi A, Hankinson SE, Hu FB, Duffy DL, Zhao ZZ, et al: A genome-wide association study identifies novel alleles associated with hair color and skin pigmentation. PLoS Genet 4: e1000074, 2008.

11. Hunt G, Kyne S, Wakamatsu K, Ito S and Thody AJ: Nle4DPhe7 alpha-melanocyte-stimulating hormone increases the eumelanin: Phaeomelanin ratio in cultured human melanocytes. J Invest Dermatol 104: 83-85, 1995.

12. Cui R, Widlund HR, Feige E, Lin JY, Wilensky DL, Igras VE, D'Orazio J, Fung CY, Schanbacher CF, Granter SR and Fisher DE: Central role of p53 in the suntan response and pathologic hyperpigmentation. Cell 128: 853-864, 2007.

13. Kandoth C, McLellan MD, Vandin F, Ye K, Niu B, Lu C, Xie M, Zhang Q, McMichael JF, Wyczalkowski MA, et al: Mutational landscape and significance across 12 major cancer types. Nature 502: 333-339, 2013.

14. Stracquadanio G, Wang X, Wallace MD, Grawenda AM, Zhang P, Hewitt J, Zeron-Medina J, Castro-Giner F, Tomlinson IP, Goding CR, et al: The importance of p53 pathway genetics in inherited and somatic cancer genomes. Nat Rev Cancer 16: 251-265, 2016.

15. Sakamuro D, Sabbatini P, White E and Prendergast GC: The polyproline region of $\mathrm{p} 53$ is required to activate apoptosis but not growth arrest. Oncogene 15: 887-898, 1997.

16. Han J, Cox DG, Colditz GA and Hunter DJ: The p53 codon 72 polymorphism, sunburns, and risk of skin cancer in US caucasian women. Mol Carcinog 45: 694-700, 2006.

17. Stefanaki I, Stratigos AJ, Dimisianos G, Nikolaou V, Papadopoulos O, Polydorou D, Gogas H, Tsoutsos D, Panagiotou P, Kanavakis E, et al: P53 codon 72 Pro homozygosity increases the risk of cutaneous melanoma in individuals with dark skin complexion and among noncarriers of melanocortin 1 receptor red hair variants. Br J Dermatol 156: 357-362, 2007.

18. Shen H, Liu Z, Strom SS, Spitz MR, Lee JE, Gershenwald JE, Ross MI, Mansfield PF, Duvic M, Ananthaswamy HN and Wei Q: P53 codon 72 arg homozygotes are associated with an increased risk of cutaneous melanoma. J Invest Dermatol 121: 1510-1514, 2003.

19. Li C, Chen K, Liu Z, Wang LE, Gershenwald JE, Lee JE, Prieto VG, Duvic M, Grimm EA and Wei Q: Polymorphisms of TP53 Arg72Pro, but not p73 G4C14>A4TA4 and p21 Ser31Arg, contribute to risk of cutaneous melanoma. J Invest Dermatol 128: 1585-1588, 2008. 
20. Zauberman A, Flusberg D, Haupt Y, Barak Y and Oren M: A functional p53-responsive intronic promoter is contained within the human mdm2 gene. Nucleic Acids Res 23: 2584-2592, 1995.

21. Bond GL, Hu W, Bond EE, Robins H, Lutzker SG, Arva NC, Bargonetti J, Bartel F, Taubert H, Wuerl P, et al: A single nucleotide polymorphism in the MDM2 promoter attenuates the p53 tumor suppressor pathway and accelerates tumor formation in humans. Cell 119: 591-602, 2004.

22. Thunell LK, Bivik C, Wäster P, Fredrikson M, Stjernström A Synnerstad I, Rosdahl I and Enerbäck C: MDM2 SNP309 promoter polymorphism confers risk for hereditary melanoma. Melanoma Res 24: 190-197, 2014.

23. Cotignola J, Chou JF, Roy P, Mitra N, Busam K, Halpern AC and Orlow I: Investigation of the effect of MDM2 SNP309 and TP53 Arg72Pro polymorphisms on the age of onset of cutaneous melanoma. J Invest Dermatol 132: 1471-1478, 2012.

24. Firoz EF, Warycha M, Zakrzewski J, Pollens D, Wang G, Shapiro R, Berman R, Pavlick A, Manga P, Ostrer H, et al: Association of MDM2 SNP309, age of onset, and gender in cutaneous melanoma. Clin Cancer Res 15: 2573-2580, 2009.

25. Capasso M, Ayala F, Avvisati RA, Russo R, Gambale A, Mozzillo N, Ascierto PA and Iolascon A: MDM2 SNP309 and p53 arg72Pro in cutaneous melanoma: Association between SNP309 GG genotype and tumor breslow thickness. J Hum Genet 55: 518-524, 2010.

26. Rovite V, Wolff-Sagi Y, Zaharenko L, Nikitina-Zake L, Grens E and Klovins J: Genome database of the latvian population (LGDB): Design, goals, and primary results. J Epidemiol 28: 353-360, 2018

27. Ozola A, Ruklisa D and Pjanova D: Association of the 16q24.3 region gene variants rs1805007 and rs4785763 with heightened risk of melanoma in latvian population. Meta Gene 18: 87-92, 2018.

28. Pliss L, Timša L, Rootsi S, Tambets K, Pelnena I, Zole E, Puzuka A, Sabule A, Rozane S, Lace B, et al: Y-Chromosoma lineages of latvians in the context of the genetic variation of the eastern-baltic region. Ann Hum Genet 79: 418-430, 2015.

29. O'Reilly PF, Hoggart CJ, Pomyen Y, Calboli FC, Elliott P, Jarvelin MR and Coin LJ: MultiPhen: Joint model of multiple phenotypes can increase discovery in GWAS. PLoS One 7: e34861, 2012.

30. Antonopoulou K, Stefanaki I, Lill CM, Chatzinasiou F, Kypreou KP, Karagianni F, Athanasiadis E, Spyrou GM, Ioannidis JPA, Bertram L, et al: Updated field synopsis and systematic meta-analyses of genetic association studies in cutaneous melanoma: The MelGene database. J Invest Dermatol 135 1074-1079, 2015

31. Gudbjartsson DF, Sulem P, Stacey SN, Goldstein AM, Rafnar T, Sigurgeirsson B, Benediktsdottir KR, Thorisdottir K, Ragnarsson R, Sveinsdottir SG, et al: ASIP and TYR pigmentation variants associate with cutaneous melanoma and basal cell carcinoma. Nat Genet 40: 886-891, 2008.

32. Kennedy C, ter Huurne J, Berkhout M, Gruis N, Bastiaens M, Bergman W, Willemze R and Bavinck JN: Melanocortin 1 receptor $(\mathrm{MC} 1 \mathrm{R})$ gene variants are associated with an increased risk for cutaneous melanoma which is largely independent of skin type and hair color. J Invest Dermatol 117: 294-300, 2001.

33. Guedj $M$, Bourillon $A$, Combadières $C$, Rodero $M$, Dieudé $P$, Descamps V, Dupin N, Wolkenstein P, Aegerter P, Lebbe C, et al: Variants of the MATP/SLC45A2 gene are protective for melanoma in the french population. Hum Mutat 29: 1154-1160, 2008

34. Demenais F, Corda E, Barrett J, Iles M, Gillanders EM, Goldstein AM, Kanetsky PA, Bakker E, Bishop DT, Newton-Bishop JA, et al: Importance of sequencing rare variants after a genome-wide association study (GWAS): The MC1R gene, 16q24 region and melanoma story. Genet Epidemiol 33: 757-758, 2009.

35. Nan H, Kraft P, Qureshi AA, Guo Q, Chen C, Hankinson SE, Hu FB, Thomas G, Hoover RN, Chanock S, et al: Genome-wide association study of tanning phenotype in a population of european ancestry. J Invest Dermatol 129: 2250-2257, 2009.
36. Beckman G, Birgander R, Sjalander A, Saha N, Nolmberg PA, Kivela A and Beckman L: Is p53 polymorphism maintained by natural selection? Hum Hered 44: 266-270, 1994.

37. Oliveira C, Rinck-Junior JA, Lourenço GJ, Moraes AM and Lima CS: Assessment of the XPC (A2920C), XPF (T30028C), TP53 (Arg72Pro) and GSTP1 (Ile105Val) polymorphisms in the risk of cutaneous melanoma. J Cancer Res Clin Oncol 139: 1199-1206, 2013

38. Geng P, Liao Y, Ruan Z and Liang H: Increased risk of cutaneous melanoma associated with p53 Arg72Pro polymorphism. PLoS One 10: e0118112, 2015

39. Gwosdz C, Scheckenbach K, Lieven O, Reifenberger J, Knopf A, Bier $\mathrm{H}$ and Balz V: Comprehensive analysis of the p53 status in mucosal and cutaneous melanomas. Int J Cancer 118: 577-582, 2006.

40. Bastiaens MT, Struyk L, Tjong-A-Hung SP, Gruis N, ter Huurne J, Westendorp RG, Vermeer BJ, Bavinck JN and ter Schegget J: Cutaneous squamous cell carcinoma and p53 codon 72 polymorphism: A need for screening? Mol Carcinog 30: 56-61, 2001.

41. Povey JE, Darakhshan F, Robertson K, Bisset Y, Mekky M, Rees J, Doherty V, Kavanagh G, Anderson N, Campbell H, et al: DNA repair gene polymorphisms and genetic predisposition to cutaneous melanoma. Carcinogenesis 28: 1087-1093, 2007.

42. Xiao W, Du N, Huang T, Guo J, Mo X, Yuan T, Chen Y, Ye T, $\mathrm{Xu} \mathrm{C}$, Wang W, et al: TP53 Mutation as potential negative predictor for response of anti-CTLA-4 therapy in metastatic melanoma. EBioMedicine 32: 119-124, 2018.

43. Raimondi S, Sera F, Gandini S, Iodice S, Caini S, Maisonneuve P and Fargnoli MC: MC1R variants, melanoma and red hair color phenotype: A meta-analysis. Int J Cancer 122: 2753-2760, 2008.

44. Nan H, Qureshi AA, Hunter DJ and Han J: A functional SNP in the MDM2 promoter, pigmentary phenotypes, and risk of skin cancer. Cancer Causes Control 20: 171-179, 2009.

45. Oliveira C, Lourenço GJ, Rinck-Junior JA, Cintra ML, Moraes AM and Lima CS: Association between genetic polymorphisms in apoptosis-related genes and risk of cutaneous melanoma in women and men. J Dermatol Sci 74: 135-141, 2014.

46. Qin J, Cong X, Jin J, Chu Z, Gu X and Cai Y: Association between MDM2 SNP309 and skin cancer: A meta-analysis of case-control studies. J Dermatol Sci 79: 171-173, 2015.

47. Landi MT, Kanetsky PA, Tsang S, Gold B, Munroe D, Rebbeck T, Swoyer J, Ter-Minassian M, Hedayati M, Grossman L, et al: MC1R, ASIP, and DNA repair in sporadic and familial melanoma in a mediterranean population. J Natl Cancer Inst 97: 998-1007, 2005.

48. Fargnoli MC, Spica T, Sera F, Pellacani G, Chiarugi A, Seidenari S, Carli P, Chimenti S and Peris K: Re: MC1R, ASIP, and DNA repair in sporadic and familial melanoma in a mediterranean population. J Natl Cancer Inst 98: 144-145, 2006.

49. Taylor NJ, Busam KJ, From L, Groben PA, Anton-Culver H, Cust AE, Begg CB, Dwyer T, Gallagher RP, Gruber SB, et al: Inherited variation at MC1R and histological characteristics of primary melanoma. PLoS One 10: e0119920, 2015.

50. Davies JR, Randerson-Moor J, Kukalizch K, Harland M, Kumar R, Madhusudan S, Nagore E, Hansson J, Höiom V, Ghiorzo P, et al: Inherited variants in the MC1R gene and survival from cutaneous melanoma: A BioGenoMEL study. Pigment Cell Melanoma Res 25: 384-394, 2012.

51. Rajabi P, Karimian P and Heidarpour M: The relationship between MDM2 expression and tumor thickness and invasion in primary cutaneous malignant melanoma. J Res Med Sci 17: $452-455,2012$.

This work is licensed under a Creative Commons Attribution-NonCommercial-NoDerivatives 4.0 International (CC BY-NC-ND 4.0) License. 